Informational Report 1025

\title{
Evaluation of Radioactive Aerosols in United States Underground Coal Mines
}

By R. L. Rock, G. Svilar, R. T. Beckman, and D. D. Rapp

Denver Technical Support Center, Denver, Colo. 


\section{DISCLAIMER}

This report was prepared as an account of work sponsored by an agency of the United States Government. Neither the United States Government nor any agency Thereof, nor any of their employees, makes any warranty, express or implied, or assumes any legal liability or responsibility for the accuracy, completeness, or usefulness of any information, apparatus, product, or process disclosed, or represents that its use would not infringe privately owned rights. Reference herein to any specific commercial product, process, or service by trade name, trademark, manufacturer, or otherwise does not necessarily constitute or imply its endorsement, recommendation, or favoring by the United States Government or any agency thereof. The views and opinions of authors expressed herein do not necessarily state or reflect those of the United States Government or any agency thereof. 


\section{DISCLAIMER}

Portions of this document may be illegible in electronic image products. Images are produced from the best available original document. 
CONTENTS

$\underline{\text { Page }}$

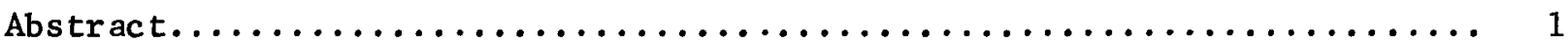

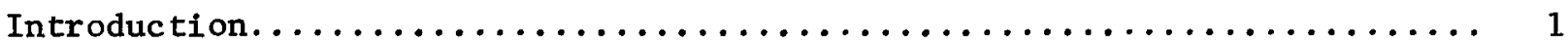

Radioactive aerosols due to radon and thoron decay............... 2

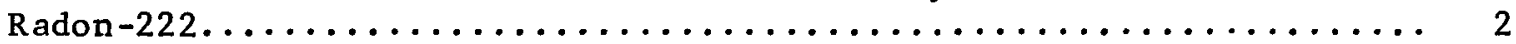

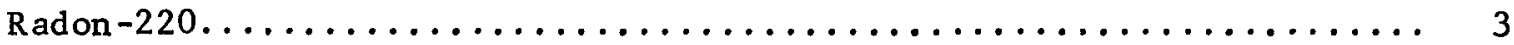

Sampling methods and equipment...................... 4

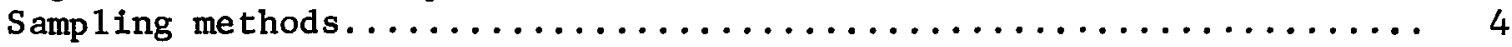

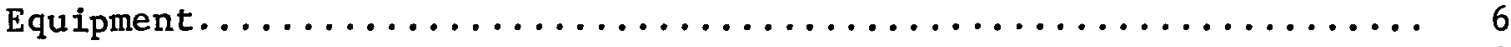

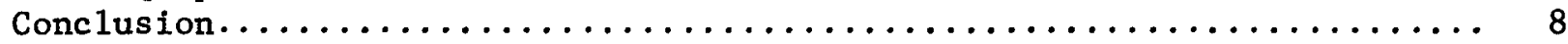

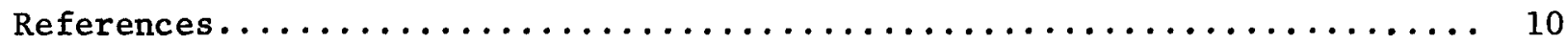

ILLUSTRATIONS

1. Radon decay scheme.............................. 3

2. Thoron decay scheme.............................. 4

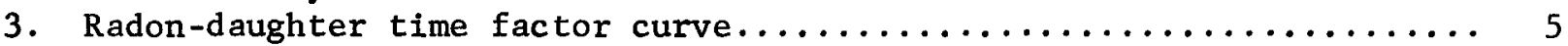

4. Thoron-daughter time factor curve...................... 5

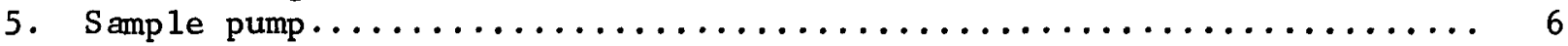

6. Filter holder and filter............................ 7

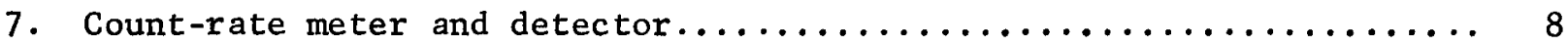

8. Digital scaler and detector......................... 8

TABLE

1. Summary of radioactive aerosol samples by State............... 9 


\title{
EVALUATION OF RADIOACTIVE AEROSOLS IN UNITED STATES UNDERGROUND COAL MINES
}

by

\author{
R. L. Rock, 1 G. Svilar, 2 R. T. Beckman, 3 and D. D. Rapp 4
}

\begin{abstract}
Radon and its alpharradiation-emitting daughter products are known to present a health hazard in a wide variety of nonuranium underground mines (1). ${ }^{5}$ For this reason, Mining Enforcement and Safety Administration (formerly Health and Safety Activity, U.S. Bureau of Mines) Coal Mine Health and Safety personne $1^{6} 7$ commenced an evaluative radioactive aerosol sampling program in eastern underground coal mines in 1969. In order to provide information necessary for a complete summary of the occurrence of radioactive aerosols in U.S. coal mines, several coal mines in the Western United States were sampled by MESA, Denver Technical Support Center personne $1^{8}$ during the period September 1974-March 1975.

Although not a11 underground coal mines were sampled, an attempt was made to evaluate representative mines from each coal producing district and major coal seam.

This paper describes the general health problem investigated, evaluation methods employed, and summarizes the data obtained.

\section{INTRODUCTION}

The health hazard from radioactive aerosols (radon daughters) has been given widespread attention in the United States for the last 20 years. Epidemiological studies of uranium miners have shown an increase in lung cancer

${ }^{1}$ Chief, Radiation Group.

${ }^{2}$ Staff Specialist, Coal Mine Health and Safety.

${ }^{3}$ Mining engineer.

${ }^{4}$ Mining engineering technician.

${ }^{5}$ Underlined numbers in parentheses refer to items in the reference list at the end of this report.

${ }^{6}$ Jack Crawford, Asst. Administrator, MESA, Coal Mine Health and Safety.

${ }^{7}$ George Svilar.

${ }^{8}$ Donald D. Rapp and Ralph W. Teller, mining engineering technicians, MESA, Denver Technical Support Center.
\end{abstract}


which is statistically significant above that of the normal population. Miners exposed to more than 120 working level months (WLM) ${ }^{9}$ show a definite susceptibility to this disease (2), but a safe threshold exposure value has not been indicated.

The fact that radon daughters ${ }^{10}$ occur in a wide variety of underground mines is not surprising because all that is required is the presence of abnormal amounts of radium-226 or thorium-232 in the product being mined or in the surrounding host rock. These two elements are common constituents, in trace amounts, within the earth's crust. Ground water can carry dissolved radon gas into otherwise nonradioactive environments; therefore, under unusual circumstances, neither the immediate host rock nor the minable product need be radioactive for a radiation health problem to exist.

Anomalous amounts of uranium have been found in certain coal deposits. Lignite in North Dakota has been mined in an attempt to exploit its uranium content. One of the authors ${ }^{11}$ has personally sampled thin coal seams which averaged about 0.05 percent $\mathrm{U}_{3} \mathrm{O}_{8}$, in the Kaiparowits Plateau area of Utah. Undoubtedly there are other anomalous coal-uranium occurrences.

The current standard for individual employee cumulative annual exposure in radon daughter environments is 4 working leve 1 months (WLM). Compliance with this regulation requires that the average environmental concentration to which ful1-time employees are exposed be no greater than $0.33 \mathrm{WL}$.

\section{RADIOACTIVE AEROSOLS DUE TO RADON AND THORON DECAY}

Radon and thoron are both isotopes of radon gas ( $R n-222$ and $\mathrm{Rn}-220$, respectively) but occur as members of two different major radioactive decay series.

\section{$\underline{\text { Radon }-222}$}

Radon gas is an intermediate decay product in the uranium decay series (fig. 1). The radon gas formed by the decay of radium-226 is mobile and has a relatively long half-life (3.8 days); the gas formed in rock surrounding a mine opening will migrate toward that opening where a portion of it will enter the mine air and continue its radioactive decay. The four short-lived daughters of radon $\operatorname{RaA}(\mathrm{Po}-218)$, $\mathrm{RaB}(\mathrm{Pb}-214)$, $\mathrm{RaC}(\mathrm{Bi}-214)$, and $\mathrm{RaC}$ ' $(\mathrm{Po}-214)$, then form sequentially in the mine air. These short-lived daughters are of atomic size and readily attach to dust of respirable size. The radon itself is not retained in the lungs as are its particulate daughter products and,

${ }^{9}$ One working level month is equivalent to 173 hours of exposure at one working leve1 (the working level unit is described later in this report.

10 Both thoron and radon daughters are technically daughters of isotopes of radon. Thor on daughters originate from radon -220 while radon daughters originate from radon-222. Throughout this paper the distinction is made for purposes of clarity, but health standards, written under the broad term of radon daughters, also apply to thoron daughters.

${ }^{11}$ R. L. Rock. 


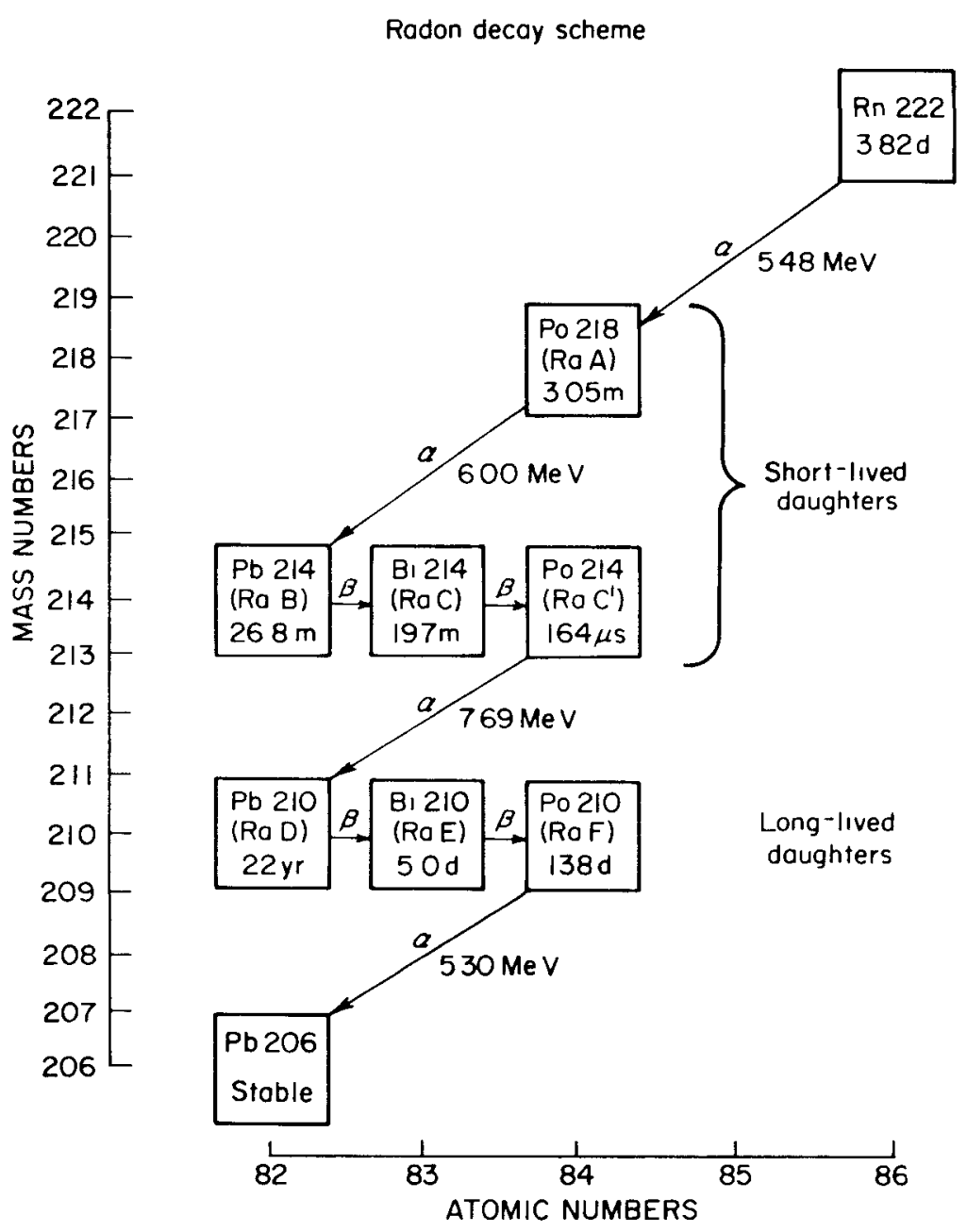

FIGURE 1. - Radon decay scheme. because of this, only that portion of the gas decaying to RaA before the gas is exhaled constitutes a health hazard. In contrast, the short-lived respirable radon daughter particulates collect in the pulmonary tract and are capable of delivering considerable alpha energy directly to the epithelial lining of the lungs in a short period of time.

\section{Radon-220}

Radon -220 , common $1 y$ called thoron, is the gaseous phase of the thorium-232 series (fig. 2). A11 thoron daughter members have an extremely short life with the exception of $\mathrm{Pb}-212$ (ThB) with a 10.6-hour halflife. This causes the concentration of $\mathrm{Pb}-212$, atoms per liter of air, to be the governing factor in the magnitude of the potential thoron-daughter health hazard. Ventilation is much more effective in controlling thoron (radon-220) daughters (because of the

relatively long half-1ife, 10.6 hours, of ThB) than it is in the control of radon-222 daughters (average ha1f-1ife, 30 minutes), hence a hazard could only be present from thoron daughters where radon-220 emanation rates are very high or ventilation rates are very low. As with radon-222 daughters, the hazard from radon-220 daughters is due to the alpha energy released in the bronchial tract by respired alpha-emitting particulates. 


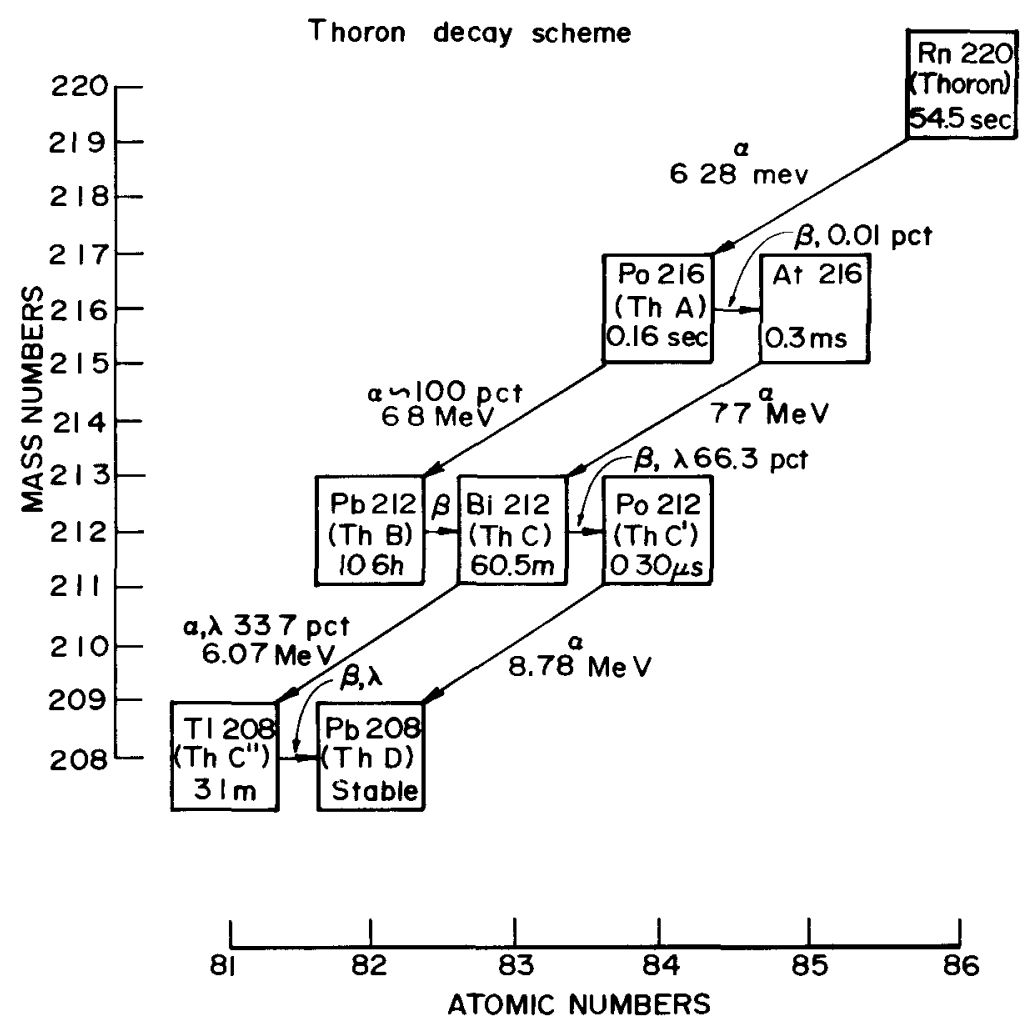

FIGURE 2. - Thoron decay scheme.

\section{SAMPLING METHODS AND EQUI PMENT}

\section{Sampling Methods}

The radon-222 daughter sampling described in this publication was performed by the standard Kusnetz method (3). The method requires drawing an air sample through a suitable filter at a known rate of at least 2 liters per minute (1pm) for 5 minutes. The particulate radon daughters collected on the filter are then counted in a suitably calibrated alpha counter at any time between 40 and 90 minutes after the end of sampling. The counts per minute (cpm) obtained from this procedure are converted to disintegrations per minute (dpm) by use of the instrument calibration fac-

tor (detector efficiency), and the resulting dpm is converted to dpm per 1iter of air by dividing by the total sample volume. The dpm per liter value is converted to working levels ${ }^{12}$ (standard unit of measurement for radon daughter concentrations) by dividing by the appropriate time factor from figure 3.

The thoron-daughter concentrations were measured using a field method developed by the U.S. Public Health Service (4) and modified by Rock (ㅁ) . The analytical method is basically the same as the one used for radon daughters with two exceptions: Because the thoron-daughter activity is much lower, a larger sample is desirable, and the time factor used is different from that used for the radon-daughter working level calculation. The sample volume may be increased by sampling for more than 5 minutes--the sample may be as long as 30 minutes without affecting the accuracy of the method. The thoron-daughter time factors given in figure 4 are applied in the same manner as the radondaughter time factors to obtain working levels. A more detailed description of thoron-daughter sampling and determination of radon-daughter working levels in the presence of significant thoron daughters is given by Rock ( $\underline{5}$ ).

\footnotetext{
i2 One working level (WL) is defined as any combination of short-lived radon daughters per liter of air which will result in the emission of $1.3 \times 10^{5}$ million electron volts (MeV) of alpha energy in decaying through RaC'. Note: Decay through ThC and $\mathrm{ThC}^{\prime}$ in the case of thoron daughters.
} 


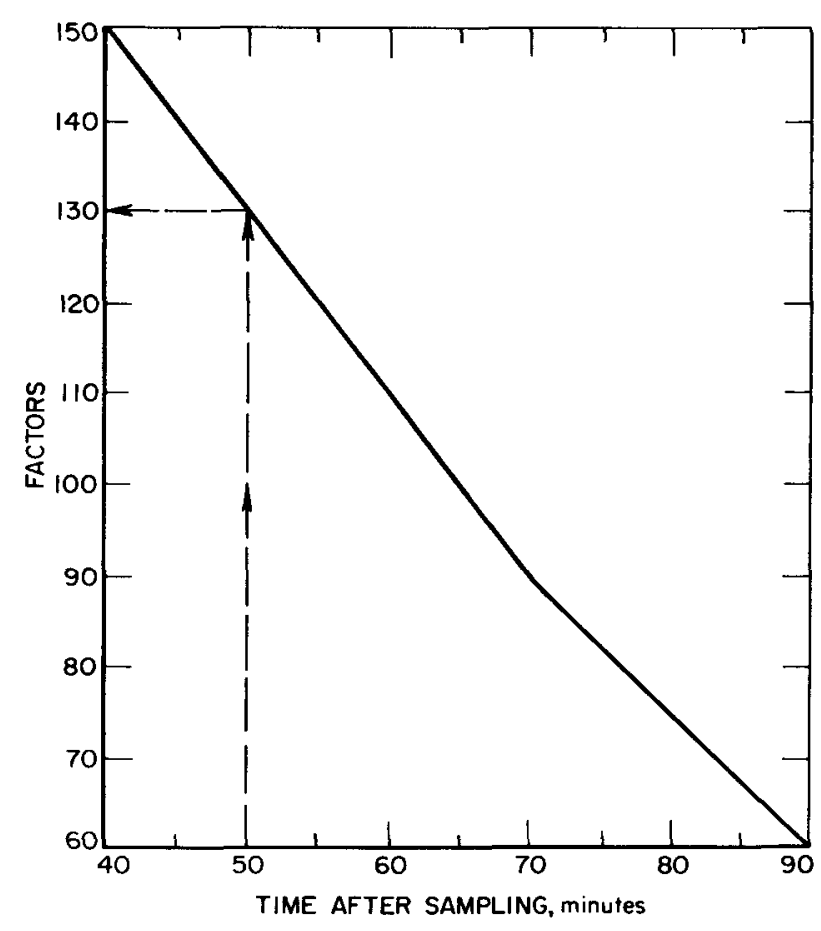

FIGURE 3. - Radon-daughter time factor curve.

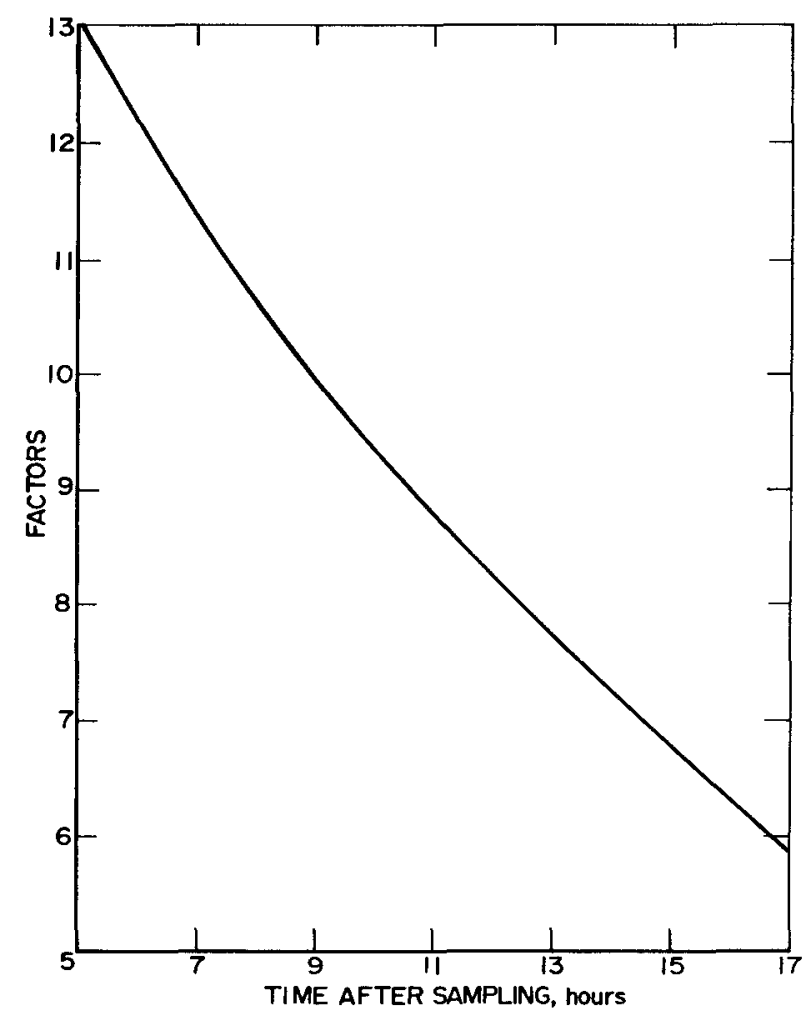

FIGURE 4. - Thoron-daughter time factor curve.

For purposes of screening the coal mines for potential health problems due to the presence of radioactive aerosols, the following procedures were employed :

1. The poorest ventilated mine areas were generally selected for sampling, including gob areas, ground water source or collection areas, and return airways. Areas where mining exposed different tectonic or sedimentary features were also often investigated.

2. Filter papers were counted as quickly as practical after samples were taken to allow the most sensitivity for the detection of any radioactivity which may have been collected. If radiation was detectable, the required analytical time was allowed to elapse and the sample was again counted to allow a working level evaluation.

3. Mines in which even slight amounts of radiation were detectable were later sampled in greater detail to determine the extent of the potential health problem. Unfortunately, sampling of eastern coal mines did not include an evaluation for thoron daughters. The coal mine specialists, who performed this work, did not have the more sophisticated field instrumentation (deve1oped later) which is vital to accurate thoron-daughter analysis. All the western coal mines sampled later were evaluated for thoron daughters in addition to radon daughters. 


\section{Equipment}

The pumps used during this survey were small battery-operated permissible units capable of drawing at least 2 liters of air per minute through a membrane or fiberglass filter; the pump is shown in figure 5 . The filters used during the initial portion of this study were $0.8 \mu$ median pore size membrane filters with suitable $25-\mathrm{mm}$ filter holders. Fiberglass filters with a minimum 99.7 percent retention of particles larger than $0.3 \mu$ (measured by DOP test) were used during the latter part of the sampling with the same type of filter holder as was used with the membrane filters. Filters and filter holders are shown in figure 6.

Two types of alpha scintillation counters were used during the study. During the initial portion of the study, a count-rate meter coupled with an alpha-scintillation detector (fig. 7) was used to determine the alpha activity on the filter; during the latter portion of the study a digital counter with an integral timer was used with the same type of alpha detector (fig. 8) as was used with the count-rate meter. The digital counter was developed after this study was initiated and offers the advantages of allowing counting for

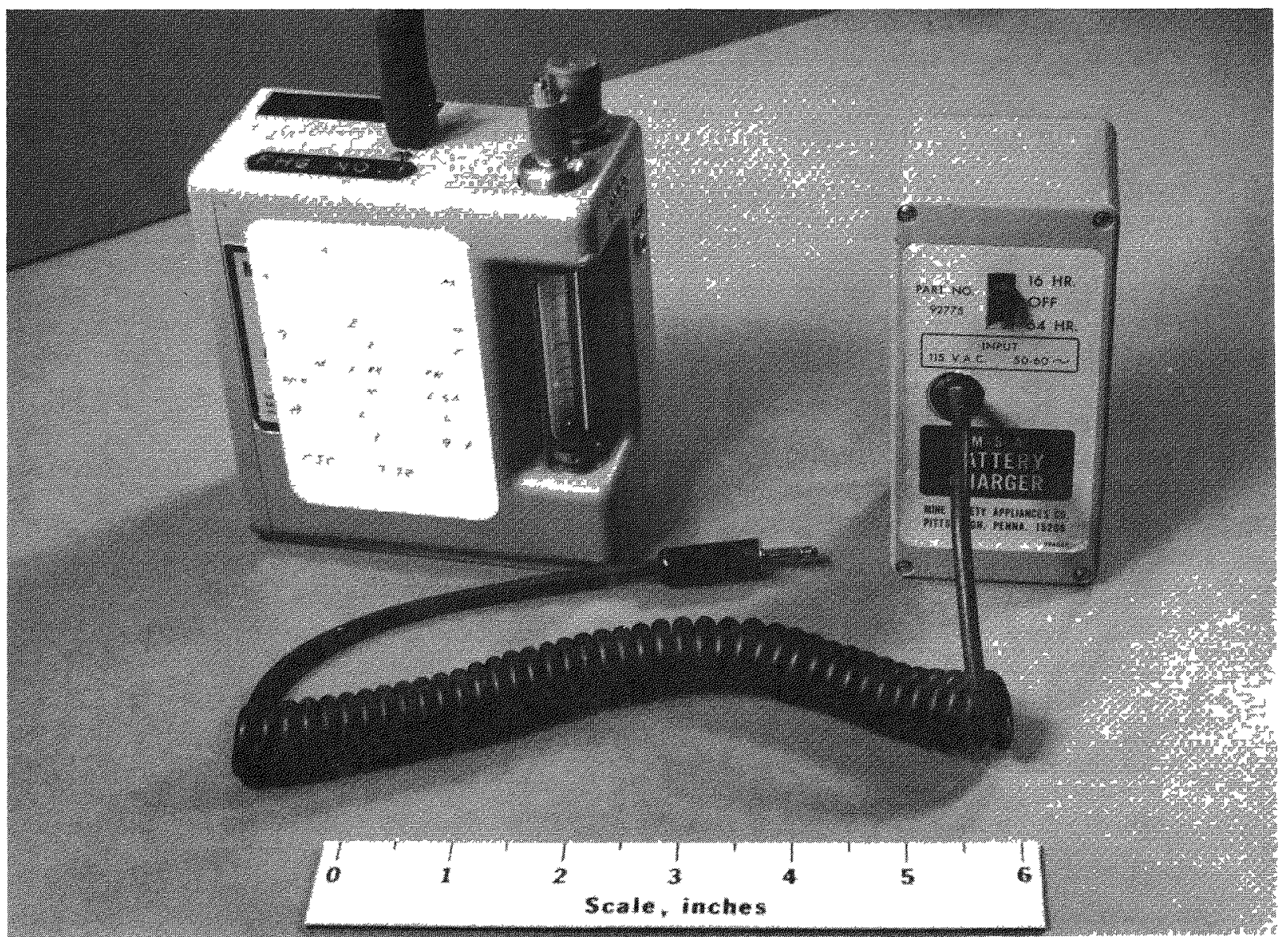

FIGURE 5. - Sample pump. 


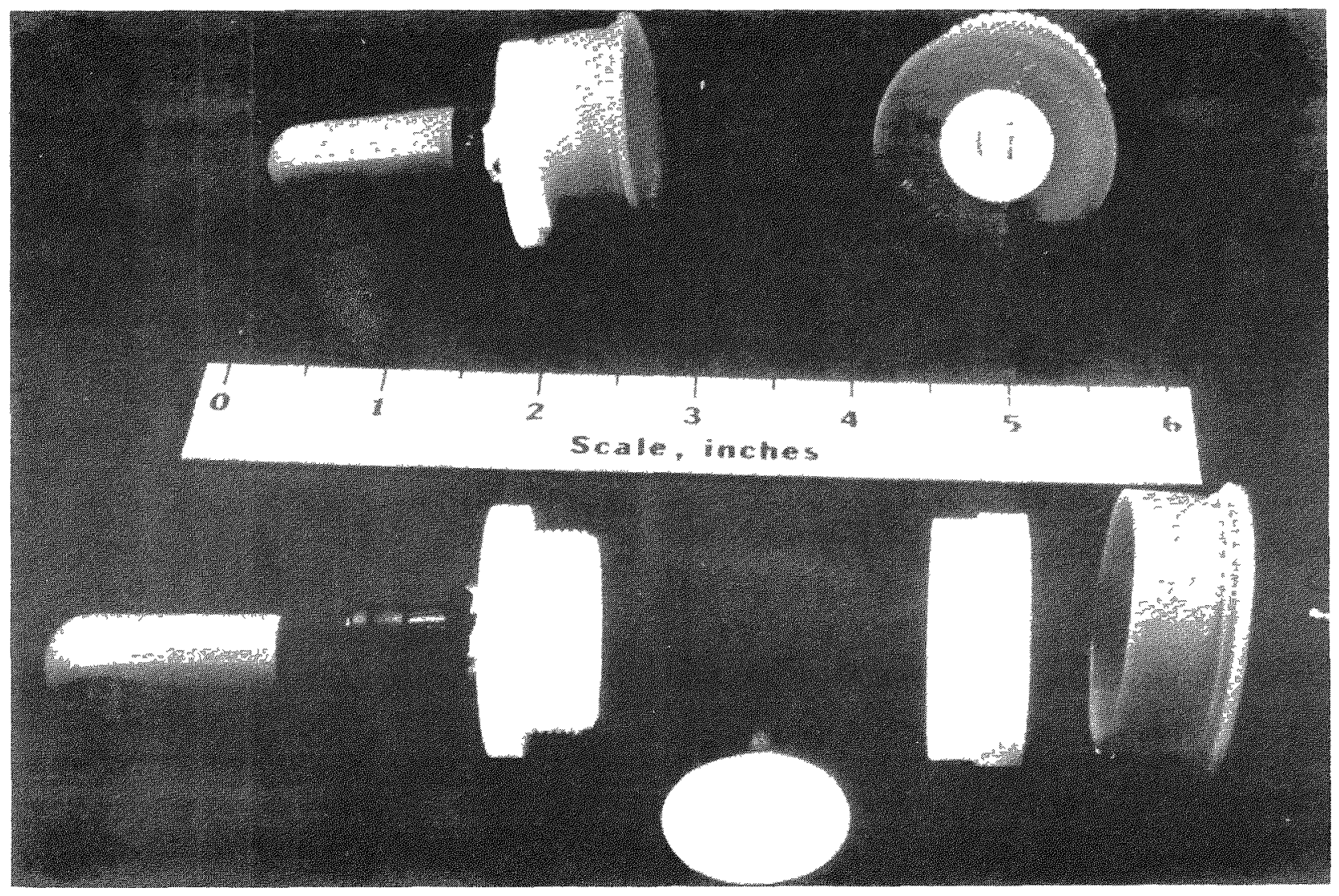

FIGURE 6. - Filter holder and filter.

1onger periods of time to obtain a more accurate average count rate and eliminating the necessity for mental averaging of an oscillating count-ratemeter needle. None of the counting equipment is permissible; therefore, all samples were counted either on the surface or in intake air.

A11 equipment used for radon-daughter measurement was carefully calibrated. The pumps must be calibrated to insure that the flow rate is accurate, and the alpha detectors must be calibrated to determine their counting efficiency. The calibration of this equipment is described in detail by Beckman (6). 


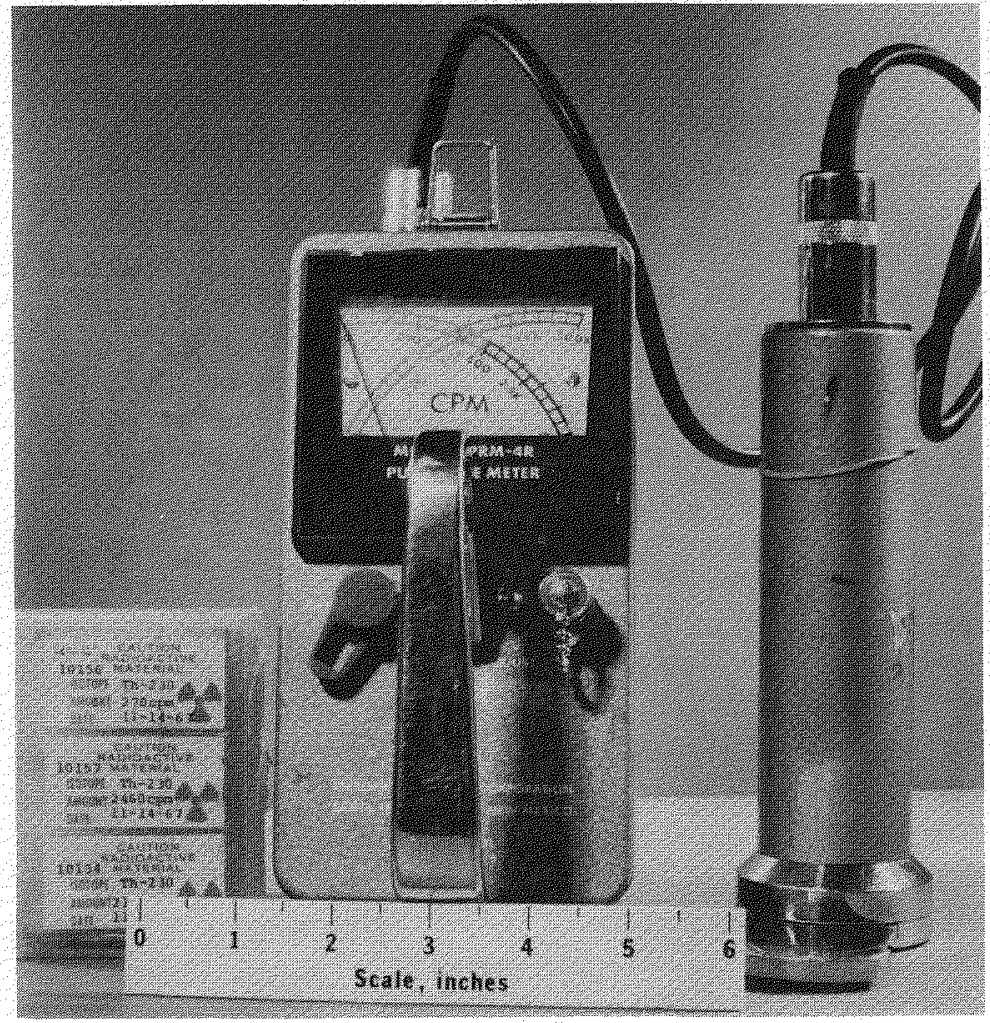

FIGURE 7. - Count-rate meter and detector.

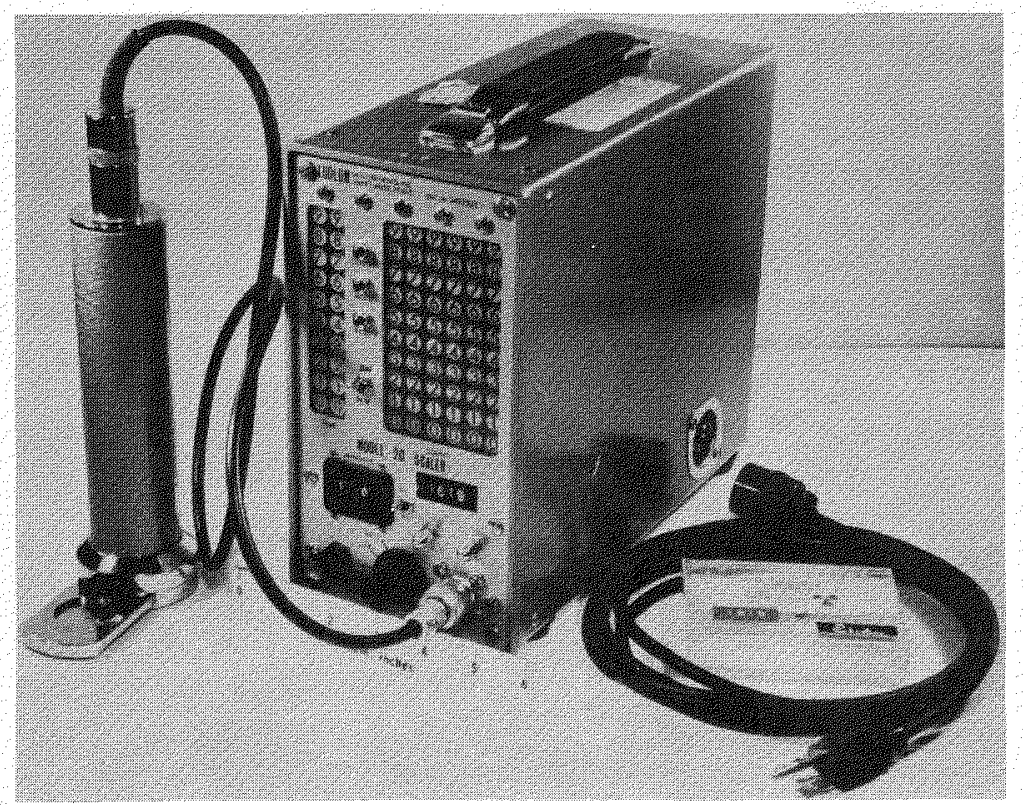

FIGURE 8. - Digital scaler and detector.

\section{CONCLUS IONS}

Fortunately only a few coal mine environments within the contiguous United States (no mines in Alaska were evaluated) were found to have radioactive aerosols present to the extent that they could constitute a potential health hazard (see table 1).

Out of a total of 223 mines evaluated by 1,581 samples, on 1 y two mines were found to have radioactive aeroso1 concentrations greater than 0.2 WL. No samples indicated concentrations in excess of $0.3 \mathrm{WL}$. Resampling of one of the mines, where concentrations were more than $0.2 \mathrm{WL}$, ind 1 cated nil radon-daughter concentrations. Although the area evaluated during the resampling was not identical to the area origina11y sampled, the increased ventilation between surveys has probably lowered the radiation level signific antly.

None of the surveyed coal mines are a serious threat to miners' health according to current Radiation Protection Guides and Standards. 
TABLE 1. - Summary of radioactive aerosol samples by State

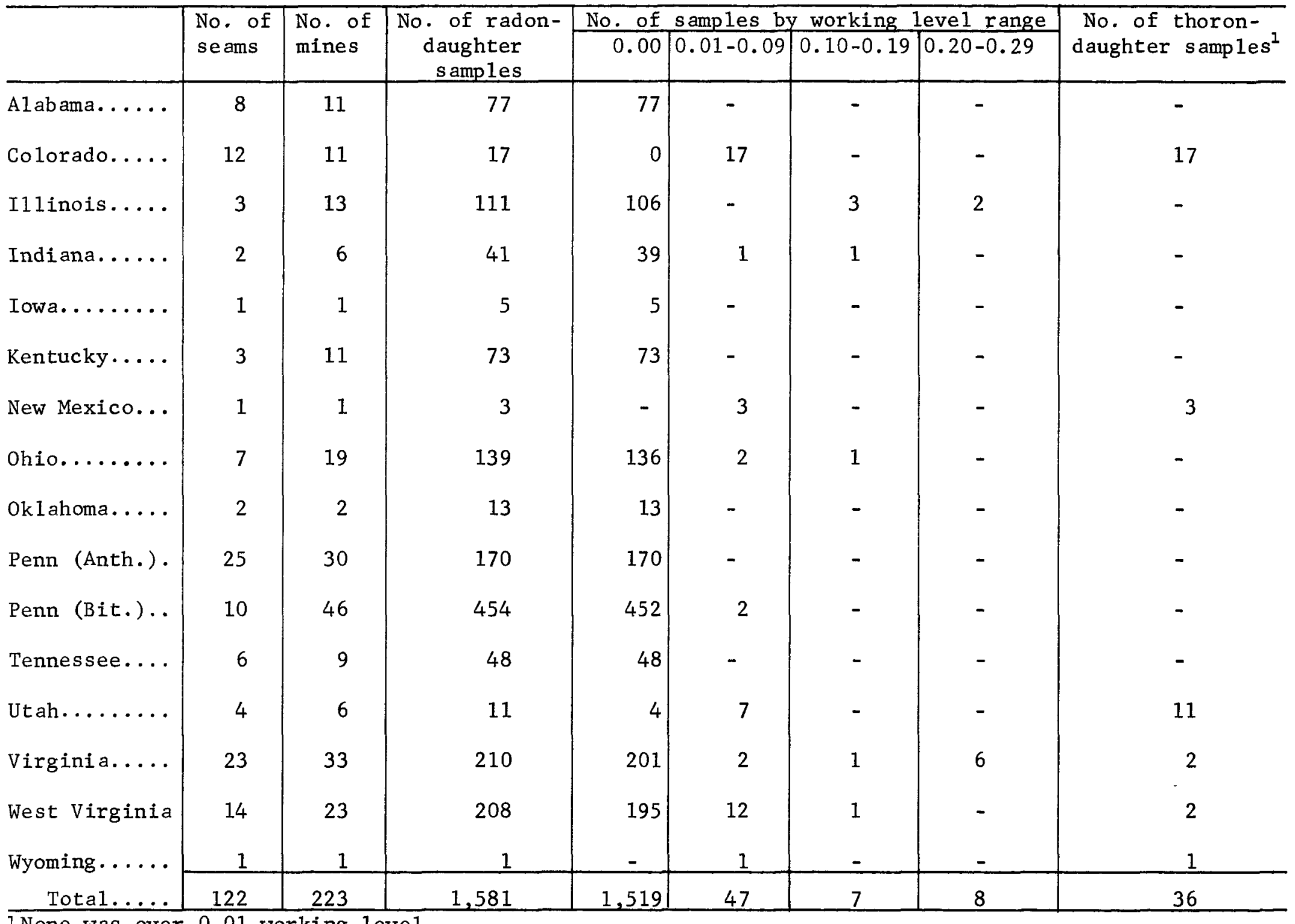

INone was over 0.01 working level. 


\section{REFERENCES}

1. USPHS Radiological Health Data and Reports, v. 9, No. 12, December 1968; from Mineral Industry Surveys, USBM, Division of Accident Prevention and Health, Bureau of Mines, Washington, D.C., May 1968.

2. Lundin, Frank E., Jr., M.D., Dr. P.H., Joseph K. Wagoner, S. D. Hyg., Victor E. Archer, M.D. Radon Daughter Exposure and Respiratory Cancer Quantitative and Temporal Aspects, 1971. Nationa1 Institute for Occupational Safety and Health National Institute of Environmental Health Sciences.

3. Kusnetz, H. L. Radon Daughters in Mine Atmospheres--A Field Method for Determining Concentrations. Ind. Hygiene Quart., v. 17, March 1956, pp. $85-88$.

4. Blanchard, Richard L., M.S., and Duncan A. Holaday, M.A. Evaluation of Radiation Hazards Created by Thoron and Thorn Daughters. American Industrial Hygiene Association Journal, v. 21, No. 3, June 1960.

5. Rock, R. L. Sampling Mine Atmospheres for Potential Alpha Energy Due to the Presence of Radon-220 (Thoron) Daughters. Mining Enforcement and Safety Administration, IR 1015, 1975.

6. Beckman, Robert T. Calibration Procedures for Radon and Radon-Daughter Measurement Equipment. Mining Enforcement and Safety Administration, IR $1005,1975$. 